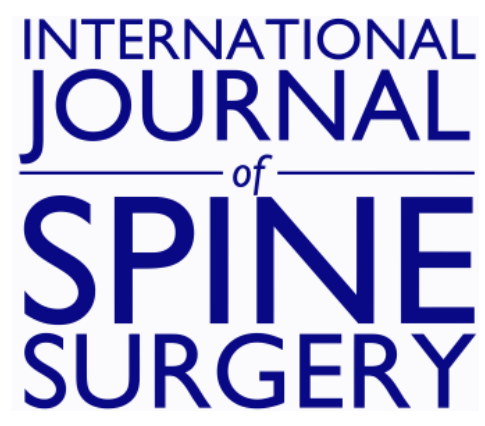

\title{
Two-Year Results of a Randomized Controlled Clinical Trial Comparing ProDisc-C and Anterior Cervical Discectomy and Fusion
}

Daniel B. Murrey, Michael E. Janssen, Susan M. Odum, Jon R. Gottlieb, Leo R. Spector and Bruce V. Darden

Int J Spine Surg 2008, 2 (2) 76-85

doi: https://doi.org/10.1016/SASJ-2007-0124-RR

http://ijssurgery.com/content/2/2/76

This information is current as of April 25, 2023.

Email Alerts Receive free email-alerts when new articles cite this article. Sign up at: http://ijssurgery.com/alerts 


\title{
Two-Year Results of a Randomized Controlled Clinical Trial Comparing ProDisc-C and Anterior Cervical Discectomy and Fusion
}

\author{
Daniel B. Murrey, MD, ${ }^{a}$ Michael E. Janssen, $M D,{ }^{b}$ Susan M. Odum, MEd, CCRC, \\ Jon R. Gottlieb, MD, ${ }^{a}$ Leo R. Spector, MD, ${ }^{a}$ and Bruce V. Darden, $M D^{a}$
}

\begin{abstract}
Background

Anterior cervical discectomy and fusion (ACDF) is a well-accepted procedure for the treatment of cervical radiculopathy. Hilibrand et al. reported that adjacent segment disease is known to occur at a rate of $2.9 \%$ per year after cervical fusion. Developers of cervical disc replacements postulate that maintaining more normal motion may reduce the rate of adjacent segment disease. The purpose of this study was to compare the 2-year efficacy and safety of ACDF and cervical total disc replacement surgery.

\section{Methods}

Eighty-seven patients from 2 sites of this 13 multicenter trial were randomized to treatment with either ACDF or cervical disc replacement surgery with the ProDisc-C (Synthes, Inc., West Chester, Pennsylvania) implant. Patient outcomes were assessed via neck disability index (NDI), visual analog pain scale (VAS), and health survey SF-36 (QualityMetric, Lincoln, Rhode Island). Forty-three patients were treated with ACDF using allograft and plating, and 44 were treated with cervical disc replacement. The average age was 44 (23 to 61) years. All surgical procedures were single level.
\end{abstract}

Results

At all measured time points, both groups showed statistically significant improvement over their preoperative baseline with regard to NDI, VAS arm and neck pain levels, SF-36 mental composite score (MCS), and physical composite score (PCS) ( $P$ $<.05)$. At 24 months, the disc replacement group showed results equivalent to the ACDF group with regard to NDI, VAS arm and neck pain, and SF-36 MCS. At 24 months, the disc replacement group showed significantly greater improvement in SF$36 \mathrm{PCS}$ as compared to the ACDF group $(P=.0359)$. Of note, there was a trend toward greater patient satisfaction in the disc replacement group as compared to the $\mathrm{ACDF}$ group ( $83 \%$ versus $71 \%, P=.144)$.

\section{Conclusions}

This study indicates that the tested disc replacement device achieves 2-year results ranging from equivalent to superior in comparison to ACDF in the treatment of symptomatic cervical disc disease. Long-term maintenance of these results has not yet been determined.

Key Words: Anterior cervical discectomy and fusion, cervical total disc replacement. SAS Journal. Spring 2008;2:76-85. DOI: SASJ-2007-0124-RR

${ }^{a}$ OrthoCarolina, Charlotte, North Carolina; ${ }^{\mathrm{b}}$ Spine Education and Research Institute, Thornton, Colorado; ${ }^{\mathrm{c}}$ OrthoCarolina Research Institute, Charlotte, North Carolina

Address correspondence to Daniel B. Murrey, MD, OrthoCarolina, 2001 Randolph Road, Charlotte, NC 28207.

Michael Jannsen, MD, has received clinical research support from Synthes Spine and has a consulting agreement with Synthes Spine. Daniel Murrey, MD, and Bruce Darden, MD, are consultants to Synthes Spine and Stryker Spine and received research support from Synthes. Bruce Darden, MD, also owns stock in Synthes.

This study is a cohort of an FDA IDE trial supported by Synthes.

Institutional Review Board approval was obtained from Presbyterian Healthcare.

\section{INTRODUCTION}

The treatment of cervical spine disorders with anterior discectomy and interbody fusion was first described by Smith and Robinson in $1958 .{ }^{1}$ Later expounded upon by Cloward ${ }^{2}$ and others, 3,4 anterior cervical discectomy and fusion (ACDF) evolved into the gold standard treatment for cervical radiculopathy and myelopathy. The clinical results of anterior cervical discectomy and fusion have been reported in the literature by various authors. ${ }^{5,6}$ The results of this procedure have been found to be quite reliable and reproducible.
However, multiple investigators ${ }^{7-9}$ have found a small but statistically significant incidence of adjacent segment disease. Whether this represents the natural sequelae of progressive spondylosis or the result of altered biomechanics from the adjacent fused segment is uncertain. ${ }^{10}$

Cervical disc replacement has emerged as a potential surgical alternative to the cervical radiculopathy and myelopathy treatment. Cervical disc replacement allows 
patients to avoid the morbidity associated with autograft harvest, potential allograft disease transmission, and plateassociated morbidity. Furthermore, in addition to allowing decompression of the neural elements, total disc replacement has the theoretical benefit of maintaining motion. Cervical disc replacement has also been shown in the laboratory to limit intradiscal pressures in adjacent segments. ${ }^{11}$ It is proposed that by preserving motion and limiting adjacent segment pressures, adjacent segment degeneration can be minimized. Clinical evidence of this remains to be shown and will require long-term follow-up studies.

The ProDisc-C (Synthes, Inc., West Chester, Pennsylvania) is a cervical disc replacement made of cobalt chrome alloy that is coated with a titanium plasma spray. An ultra-high-molecularweight polyethylene spacer sits between the 2 endplates and provides for a semi-constrained ball and socket design. A central keel on each endplate provides secure initial fixation while long-term fixation will result from bony ongrowth. With a motion profile similar to the native spine, the prosthesis allows for up to $20^{\circ}$ of flexion, extension, and lateral bending while rotation is unconstrained (Figures $1 \mathrm{~A}-1 \mathrm{~F}$ ).

Encouraging early clinical results of various cervical disc replacements have been reported in the literature. ${ }^{12-17}$ The objective of this report is to summarize the early clinical results of the ProDisc-C at 2 centers (OrthoCarolina Spine Center, Charlotte, North Carolina, and Spine Education and Research Institute, Denver, Colorado) which were part of the US Food and Drug Administration investigational device exemption (IDE) study. The purpose of the study was to compare a cervical disc replacement device with ACDF in the treatment of symptomatic cervical disc disease.

\section{MATERIALS AND METHODS}

After obtaining informed consent, patients were randomized using a blocked randomization schedule with a $1: 1$ ratio of investigational disc replacement to the control ACDF. Patients between the ages of 18 and 60 years presenting with single-level, symptomatic cervical disc disease between $\mathrm{C} 3$ and $\mathrm{C} 7$ were included. Included patients suffered from neck and/or arm pain and demonstrated a functional/neurological deficit that had either failed conservative treatment for 6 weeks or showed neurologic deterioration. In addition, a neck disability index (NDI) score of 15 (moderate disability) and objective evidence (via CT or MRI) of herniated nucleus pulposus or spondylosis were required for inclusion. Patients presenting with the following conditions were excluded from participation: predominant axial neck pain, multiple segment disease, prior fusion at an adjacent level, prior surgery at the affected level, instability (demonstrated by translation $>3$ $\mathrm{mm}$ and/or angulation $>11^{\circ}$ ), radiographic evidence of severe facet joint disease, dual energy X-ray absorptiometry (DEXA) T-score $<-2.5$ (only high-risk patients), severe spondylosis (bridging osteophytes, disc height loss $>50 \%$, absence of motion $<2^{\circ}$ ), radiographic evidence of prior fracture,

\section{Figure 1.}
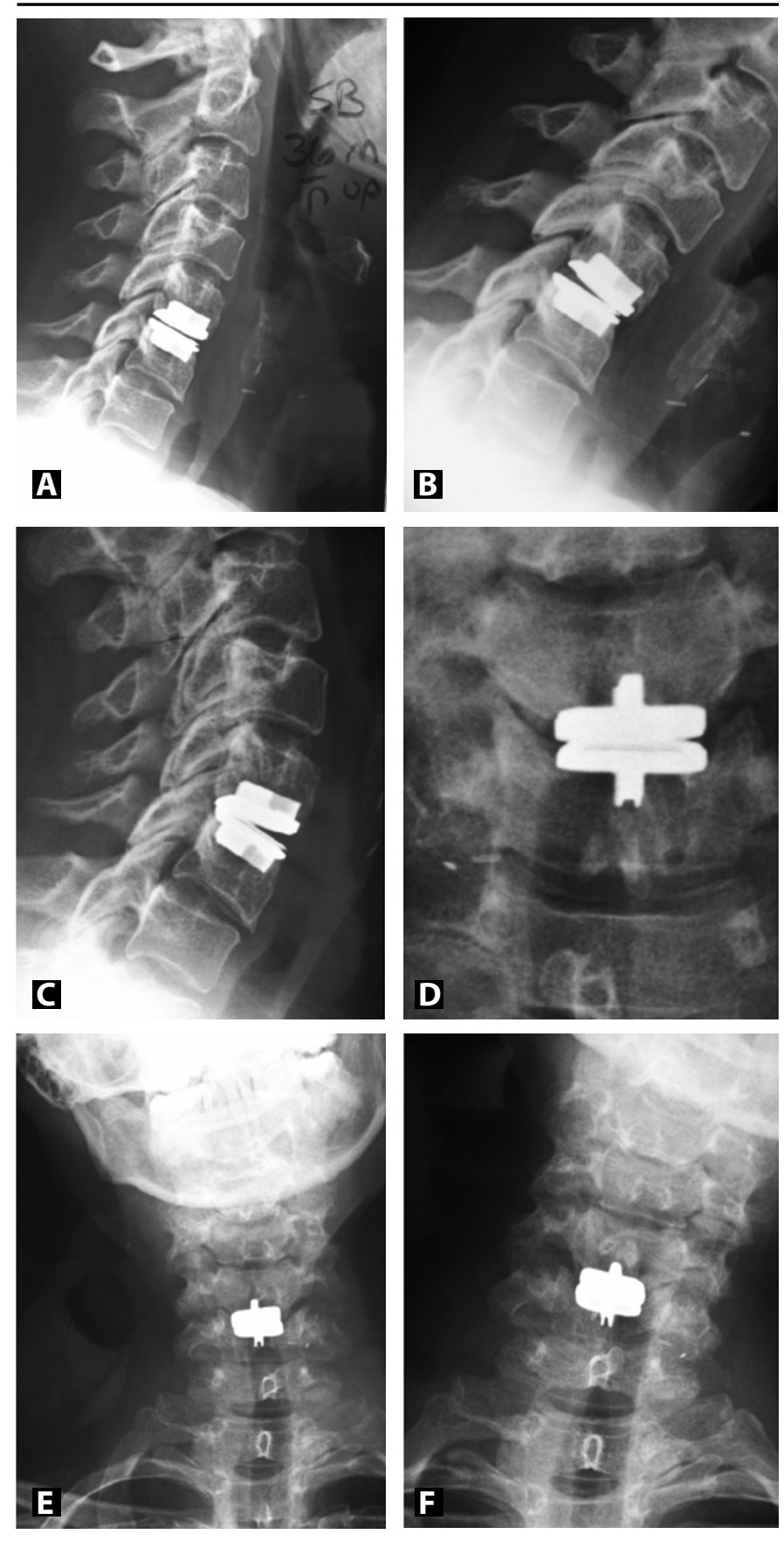

Postoperative radiographs 3 years post C5-6 artificial disc replacement with ProDisc-C. Lateral (A), flexion (B), extension (C), AP (D), side-to-side bending ( $E$ and $F$ ) films demonstrate preserved motion at the $C 5-6$ level.

pregnancy, active infection (local or systemic), metabolic bone disease of any variety, autoimmune disease, insulin dependent diabetes mellitus, HIV/AIDS, hepatitis, cancer within the past 5 years, use of immunosuppressive drugs, and arm or neck pain of undetermined etiology.

Between August 2003 and October 2004, 87 patients were enrolled from 2 of 13 sites in this multicenter, randomized, controlled clinical trial. Of the 87 patients at our 2 sites, 
44 received cervical disc replacement and 43 were treated with ACDF. All patients receiving an ACDF were treated with a standard discectomy and foraminotomy as indicated. The endplates were decorticated and an allograft spacer of individual surgeon's choice was inserted without the addition of any bone graft extenders, biologic augmentation, or other form of growth/healing stimulation. A fixed angle plate of the surgeon's choice was inserted with 4 total screws. All patients receiving disc replacement also underwent discectomy and foraminotomy, followed by insertion of the prosthesis per the manufacturer's specifications.

Table 1. Demographic Information

\begin{tabular}{|c|c|c|c|}
\hline & ACDF & ProDisc-C & $P$ value \\
\hline Gender & & & .053 \\
\hline Male & $19(44.2 \%)$ & $29(65.9 \%)$ & \\
\hline Female & $24(55.8 \%)$ & $15(34.1 \%)$ & \\
\hline Age & $44.6(6.8)^{*}$ & $43(9.4)^{*}$ & .365 \\
\hline BMI & $28.2(4.7)^{*}$ & $27.2(5.2)^{*}$ & .183 \\
\hline Race & & & .806 \\
\hline Caucasian & $40(93 \%)$ & $39(88.6 \%)$ & \\
\hline African American & $1(2.3 \%)$ & $3(6.8 \%)$ & \\
\hline Hispanic & $1(2.3 \%)$ & $0(0 \%)$ & \\
\hline Asian American & $0(0 \%)$ & $1(2.3 \%)$ & \\
\hline Other & $1(2.3 \%)$ & $1(2.3 \%)$ & \\
\hline Current Smoker & & & $>.99$ \\
\hline Yes & $18(41.9 \%)$ & $19(43.2 \%)$ & \\
\hline No & $25(58.1 \%)$ & $25(56.8 \%)$ & \\
\hline Former Smoker & & & $>.99$ \\
\hline Yes & $7(18.4 \%)$ & $7(17.9 \%)$ & \\
\hline No & $31(81.6 \%)$ & $32(82.1 \%)$ & \\
\hline Worker's Comp & & & .443 \\
\hline No & $39(90.7 \%)$ & $37(84.1 \%)$ & \\
\hline Seeking & $2(4.7 \%)$ & $1(2.3 \%)$ & \\
\hline Receiving & $2(4.7 \%)$ & $6(13.6 \%)$ & \\
\hline
\end{tabular}

Of the 44 disc replacement patients, 15 were female and 29 were male with a mean age of $43(\mathrm{SD}=9.4)$. In the ACDF group there were 24 females and 19 males with an average age of $44.6(\mathrm{SD}=6.8)$. See Table 1. The use of nonsteroidal anti-inflammatory drugs (NSAIDs) in the postoperative period was not a part of the IDE study protocol.

All patients were assessed preoperatively and postoperatively at 6 weeks, 3 months, 6 months, 12 months, 18 months, and 2 years. At each visit, patients completed self assessment questionnaires, and the physician completed a physical and neurological examination. Self assessment questionnaires included the neck disability index (NDI), a visual analog scale (VAS) measuring neck and arm pain, and SF-36 (QualityMetric, Lincoln, Rhode Island) mental composite score (MCS), and SF-36 physical composite score (PCS). Operative data included estimated blood loss and length of surgery. All of the aforementioned data from the self assessment questionnaires constituted the pre-hoc primary outcome measures.

\section{STATISTICAL METHODS}

Standard descriptive statistics were calculated. A chi-square test, or when appropriate a Fisher's exact chi-square test, was used to determine statistical significance in the levels treated, race, gender, smoking status, and worker's compensation status between each group. Wilcoxon rank sum tests were used to determine statistical significance between groups for the following variables: age (years), BMI, estimated blood loss (cc), and operative time (minutes). For the outcome variables (NDI, VAS arm and neck pain, and SF-36 MCS and PCS), Wilcoxon rank sum tests were used to determine statistical significance between the 2 treatment groups for the change in scores from preoperative to each postoperative interval. The significance level (alpha) for all statistical tests was established a priori at 0.05 .

\begin{tabular}{|c|c|c|c|}
\hline & ACDF & ProDisc-C & $P$ value \\
\hline Intraop Time (min) & $81.3(22.4)$ & $89.8(17.9)$ & .0112 \\
\hline Estimated Blood Loss (cc) & $66.5(30.4)$ & $96.6(65.9)$ & .004 \\
\hline Levels Implanted & & & .76 \\
\hline C3-4 & $0(0 \%)$ & $2(4.5 \%)$ & \\
\hline C4-5 & $3(7 \%)$ & $2(4.5 \%)$ & \\
\hline C5-6 & $24(55.8 \%)$ & $24(54.5 \%)$ & \\
\hline C6-7 & $16(37.2 \%)$ & $16(36.4 \%)$ & \\
\hline
\end{tabular}

\section{RESULTS}

Significant differences were found between treatment groups with respect to both the operative time and the estimated blood loss during surgery. The mean operative time for the ACDF group was $81.3 \mathrm{~min}(\mathrm{SD}=22.4)$ compared to $89.8 \mathrm{~min}(\mathrm{SD}=17.8)$ for the disc replacement group $(P=.011)$. The mean estimated blood loss for the ACDF group $(66.5 \mathrm{cc} ; \mathrm{SD}=30.4)$ was significantly less $(P$ $=.004)$ than the mean estimated blood loss for the disc replacement group (96.6 cc; $\mathrm{SD}=65.9)$ (Table 2$)$.

There were no statistically significant differences between treatment groups at baseline with respect to preoperative status as measured by NDI, VAS arm pain and neck pain, and SF-36 MCS and PCS. At all time points, both groups demonstrated statistically significant improvement from baseline with regard to all of the aforementioned parameters (Figures 2-6).

Significant differences were found between the groups with regard to improvement in NDI scores. At the 3-month interval, the disc replacement group showed a decrease of 34.7 from baseline while the ACDF group showed a decrease of $22.5(P=.005)$. At the 12month interval, the disc replacement group showed a decrease of 32.3 from baseline versus a decrease of 20.2 in the ACDF group $(P=.041)$ (Figure 7). There were no statistical differences found between groups at the 6-week, 6-month, 18-month, and 2-year intervals.

There were significant differences between the groups with regard to improvement in VAS arm pain. At the 3-month interval, 
the disc replacement group showed a decrease of 49.1 from baseline compared to a decrease of 32.5 in the ACDF group $(P=.0396)$. At the 12-month interval, the disc replacement group showed a decrease of 50.7 from baseline compared to a decrease of 24.8 in the ACDF group $(P=.0175)$ (Figure 8). There were no statistical differences found between groups at the 6-week, 6-month, 18-month, and 2-year intervals.

With respect to VAS neck pain, a significant difference between the groups was found. At the 3-month interval, the disc replacement group showed a decrease of 49.6 from baseline while a decrease of 32.4 was seen in the ACDF group $(P=.019)$ (Figure 9). There were no statistical differences found between groups at 6-week, 6-month, 12-month, 18month, and 2-year intervals.

There were significant differences between the groups in SF-36 PCS improvement. At the 18-month interval, the disc replacement

\section{Figure 2. SF-36 Physical Composite Score (PCS)}

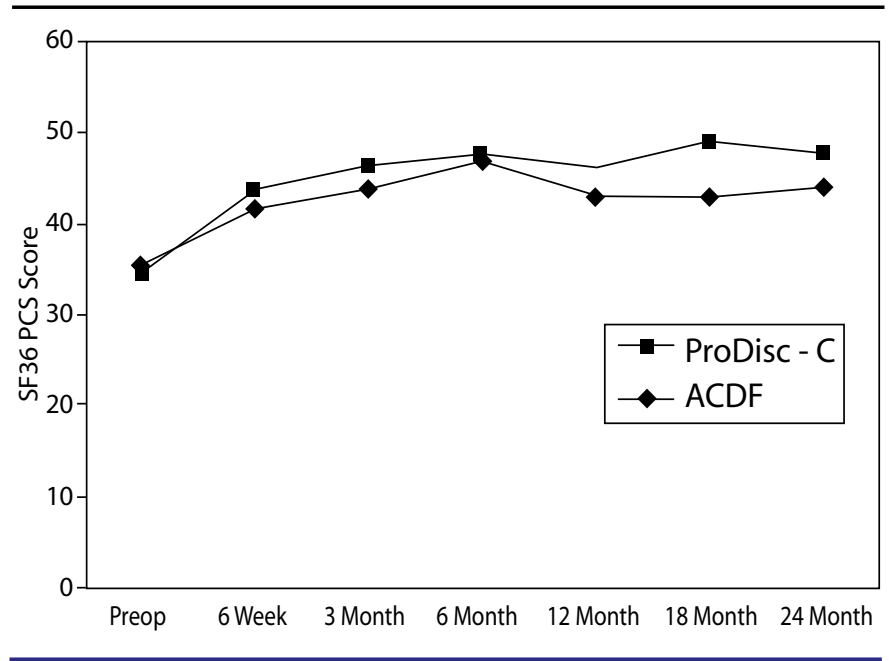

Figure 3.SF-36 Mental Composite Score (MCS)

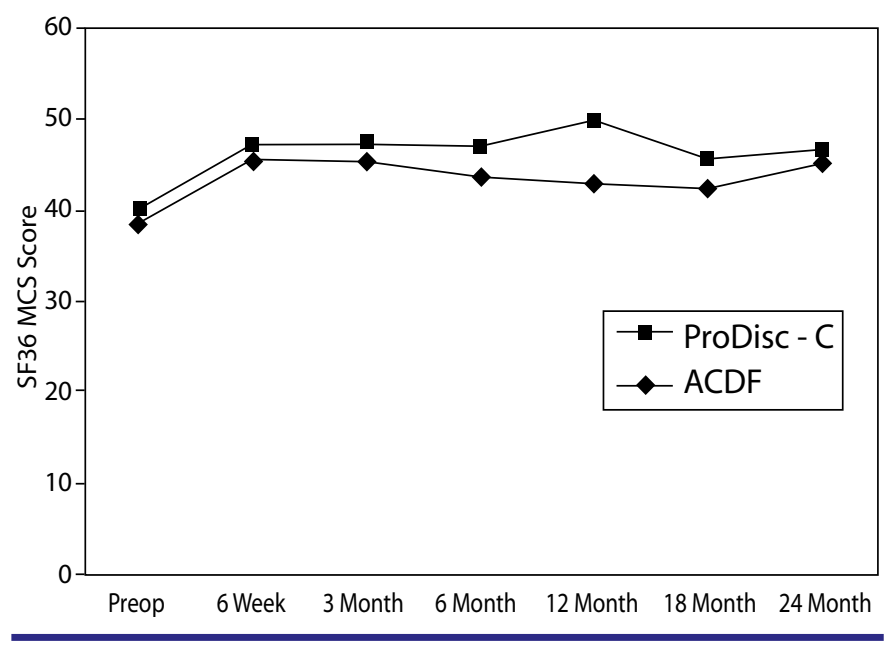

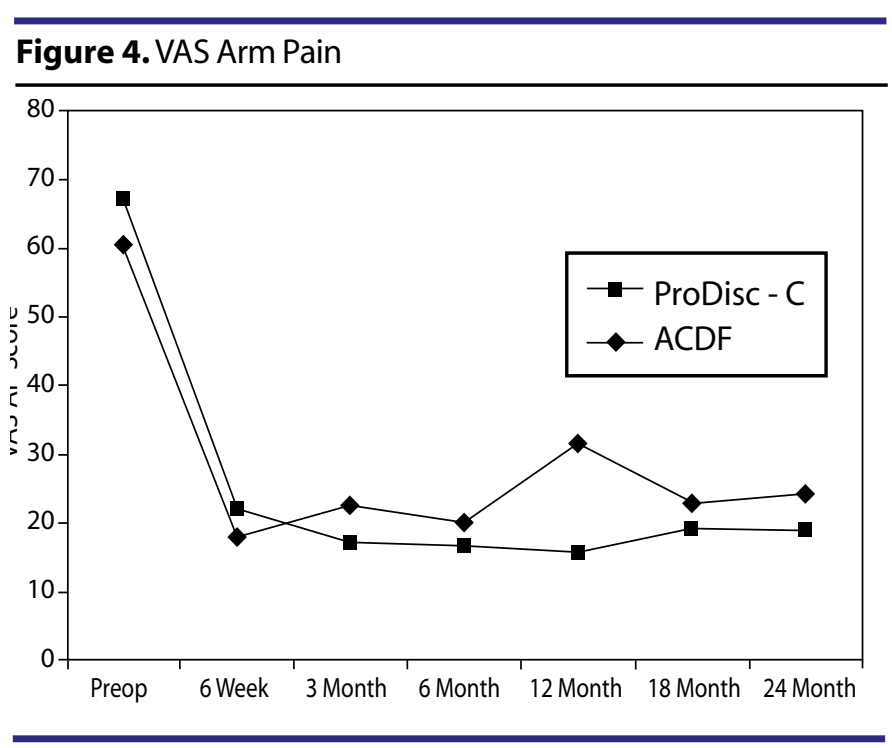

Figure 5. VAS Neck Pain

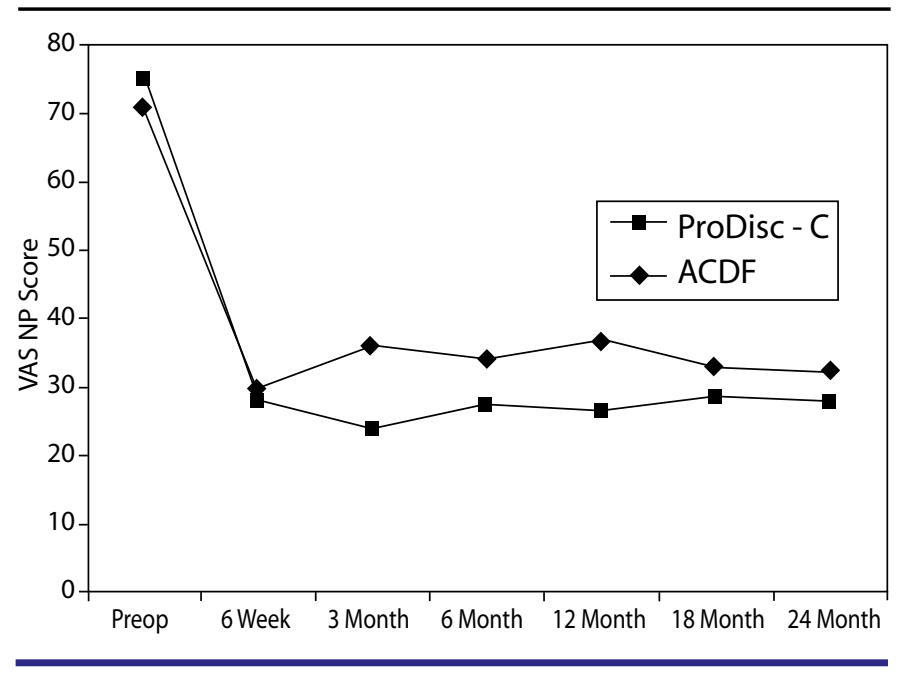

Figure 6. NDI Scores

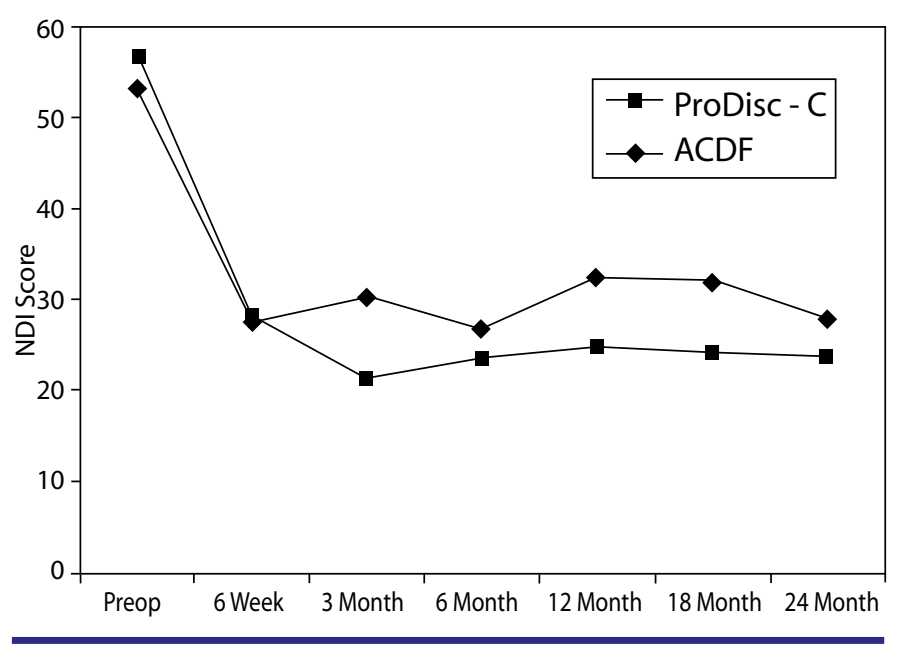


Figure 7. Decrease In NDI From Preop.

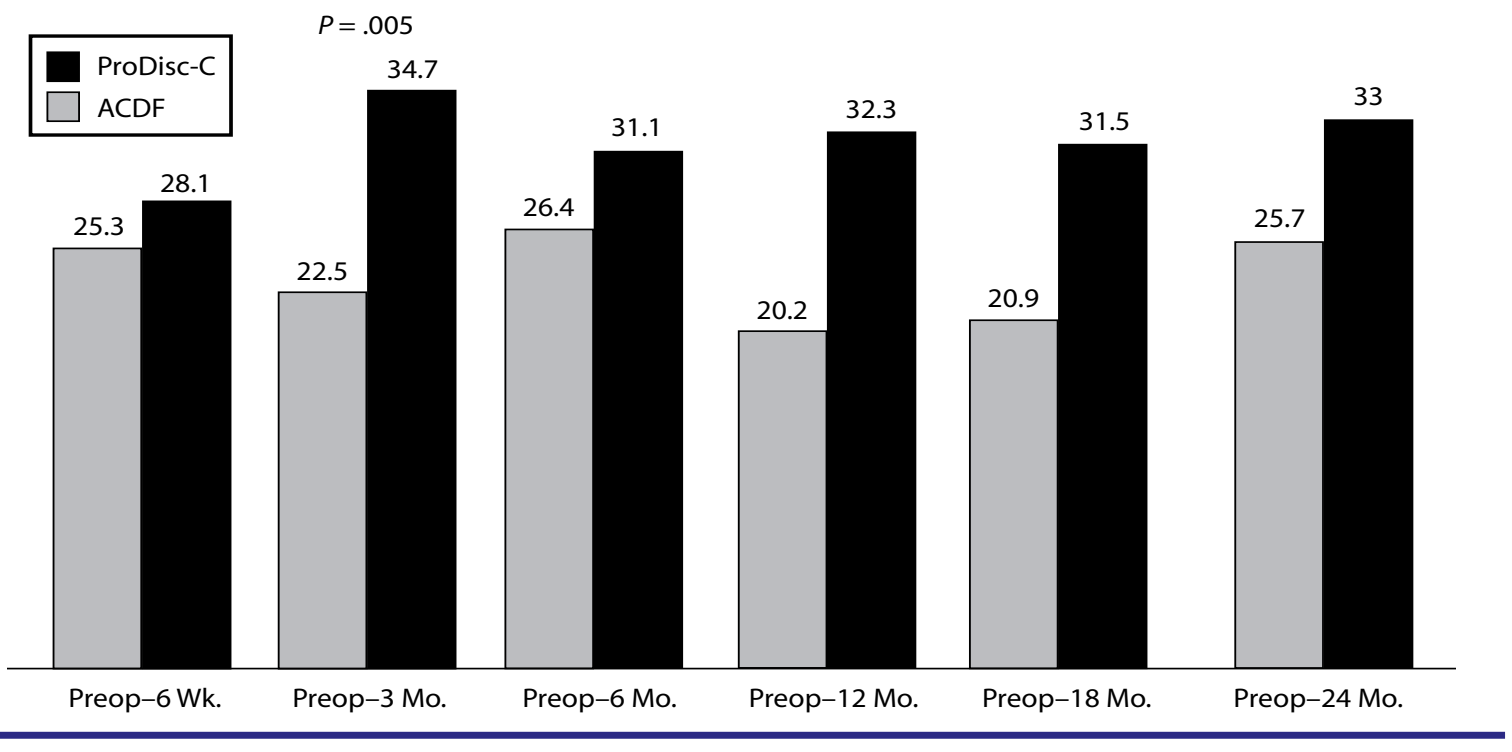

Figure 8. Decrease In VAS Arm Pain From Preop.

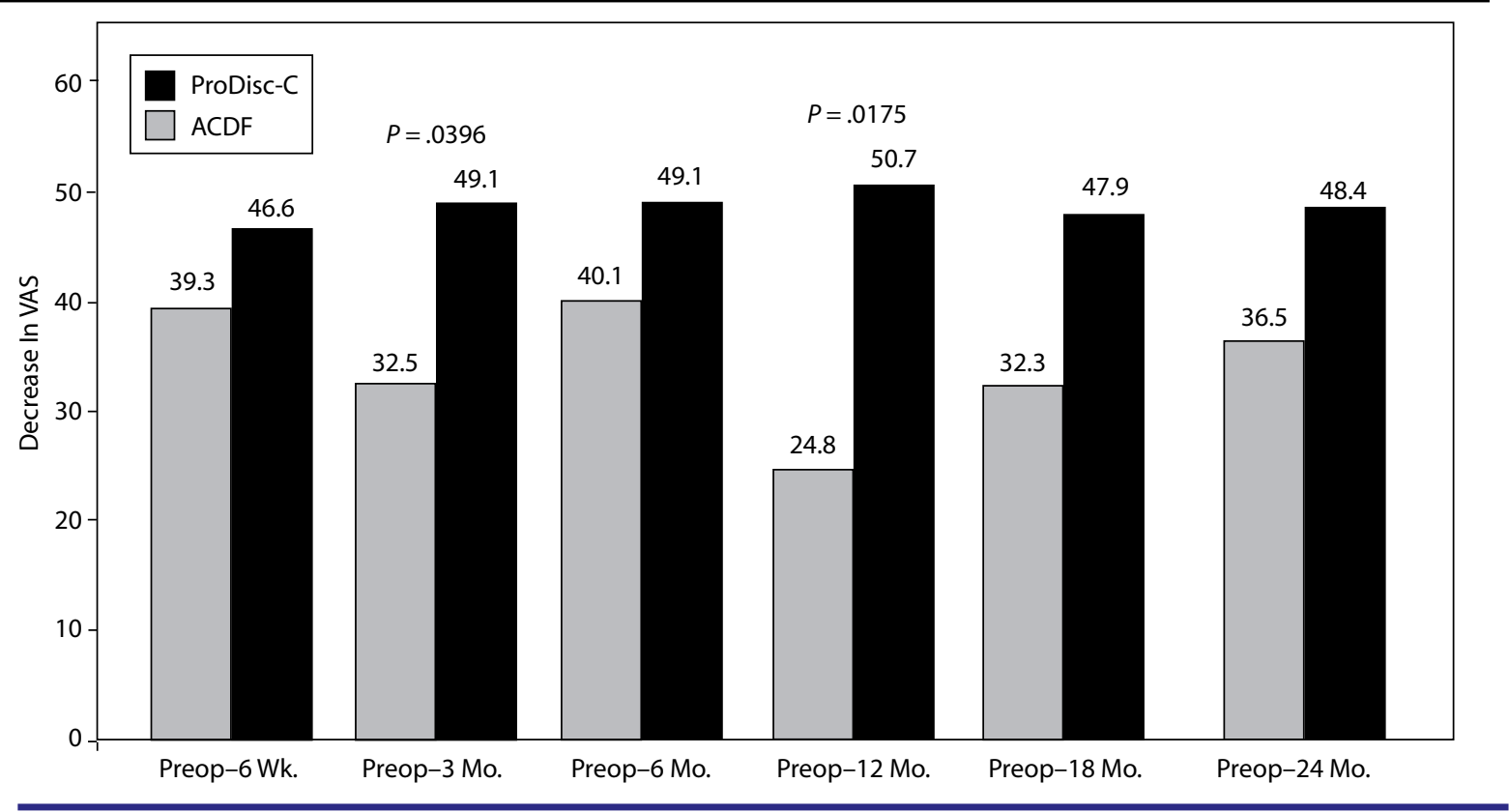

group showed an increase of 14 from baseline compared to an increase of 6.9 in the ACDF group $(P=.0043)$. At the 24-month interval, the disc replacement group showed an increase of 13 from baseline compared to an increase of 8.8 in the ACDF group $(P=.0359)$ (Figure 10). There were no statistical differences found between groups at the 6-week, 3-month, and 6-month intervals.

There was a significant difference between the groups with regard to improvement in SF-36 MCS. At the 12-month interval, the disc replacement group showed an increase of 11 from baseline compared to an increase of 2.4 in the ACDF group $(P=.0164)$ (Figure 11$)$. There were no statistical differences found between groups at the 6-week, 3-month, 6month, 18-month, and 2-year intervals.

VAS satisfaction scores were also significantly different between the groups. At the 6-month interval, the disc replacement group showed a VAS satisfaction score of $83 \%$ compared with $68.4 \%$ in the ACDF group $(P=.0328)$. At the 12-month interval, the disc replacement group showed a VAS satisfaction score of $82.1 \%$ compared to $64.8 \%$ in the ACDF group $(P=.0151)$. The trend continued at 24 months 
Figure 9. Decrease In VAS Neck Pain From Preop.

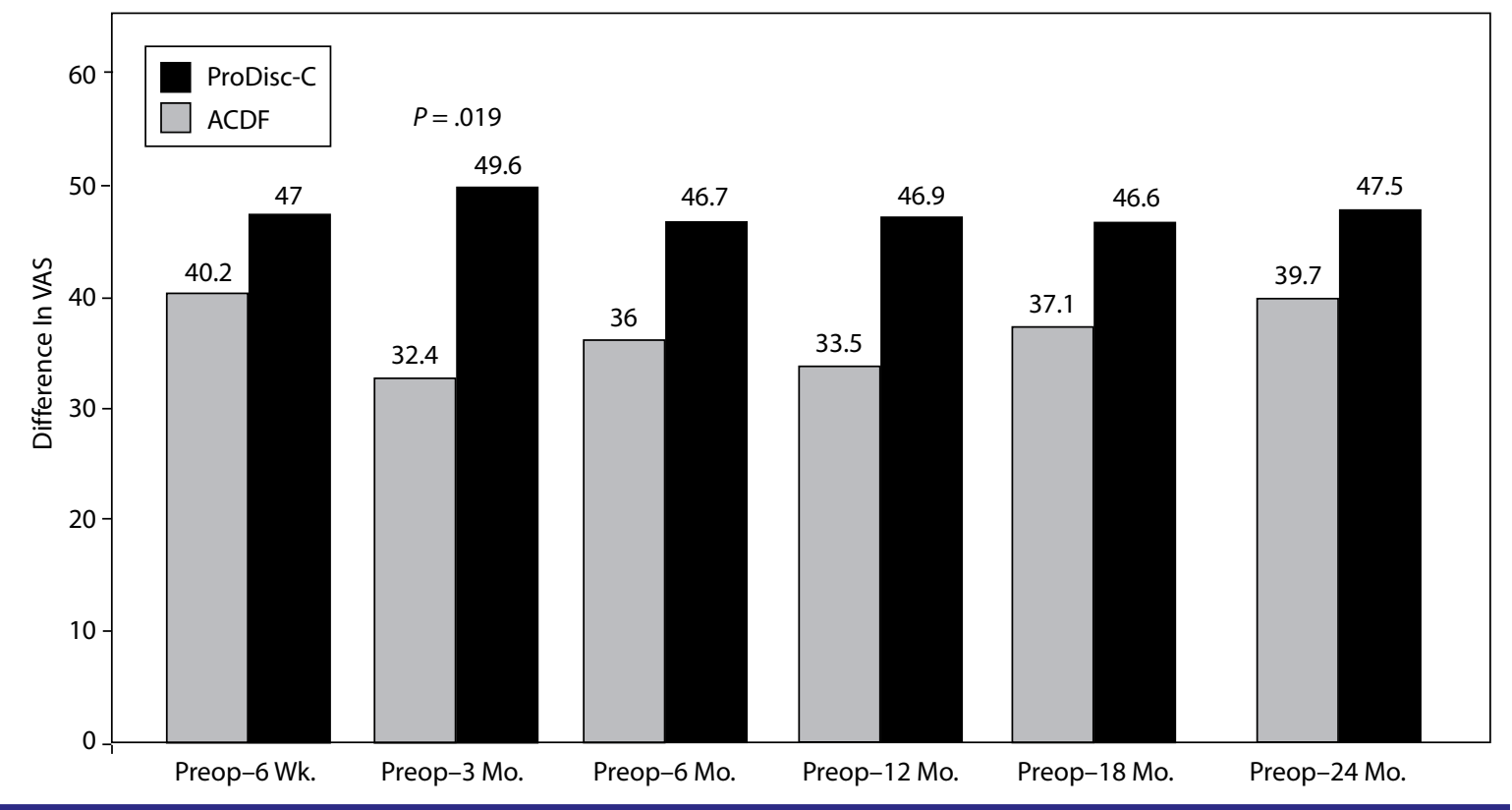

Figure 10. Increase In SF-36 PCS From Preop.

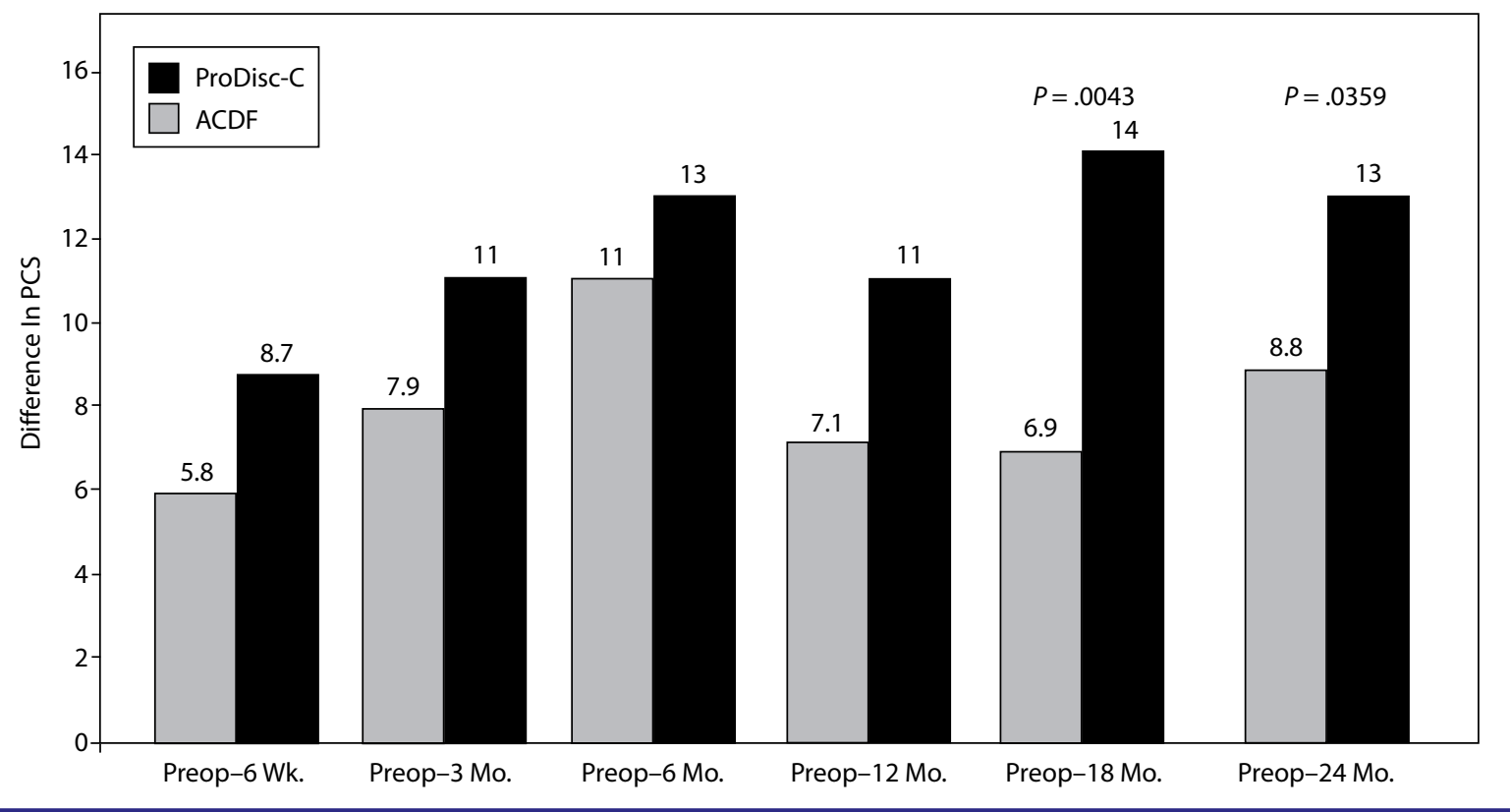

but did not achieve statistical significance (disc replacement at $82.9 \%$ and $\mathrm{ACDF}$ at $70.5 \%, P=.144$ ) (Figure 12). There were no statistical differences found between groups at the 6-week, 3-month, 18-month, and 2-year intervals.

The mean preoperative flexion to extension range of motion for the disc replacement group was 8.2 degrees. At all time points, the disc replacement group had an improved mean flexion to extension range of motion (Figure 13).

There was 1 serious adverse event in the disc replacement group and 6 in the ACDF group, all of which required re- operation. In addition, 1 ACDF patient had a superficial wound infection. As such the overall complication rates were $2.3 \%$ for disc replacement versus $16.3 \%$ for ACDF.

The disc replacement patient had persistent axial neck pain and underwent conversion to fusion by a surgeon outside the IDE trial. Of the 6 patients in the ACDF group, 4 had revisions for painful pseudoarthroses, 1 had plate and graft subsidence, and 1 developed symptomatic adjacent segment

disease.
.com/ by guest on April 25, 2023 


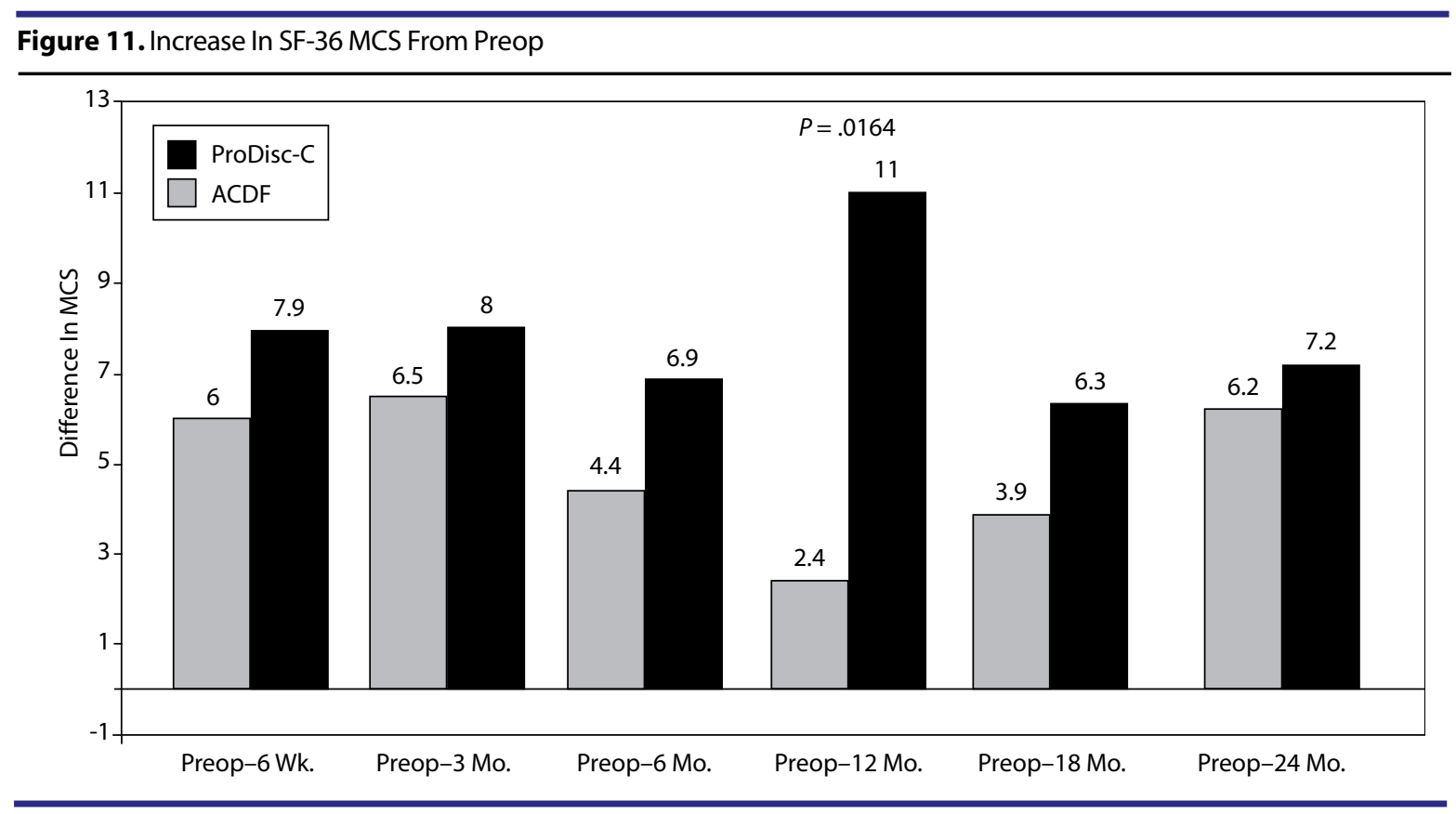

Figure 12. VAS Satisfaction

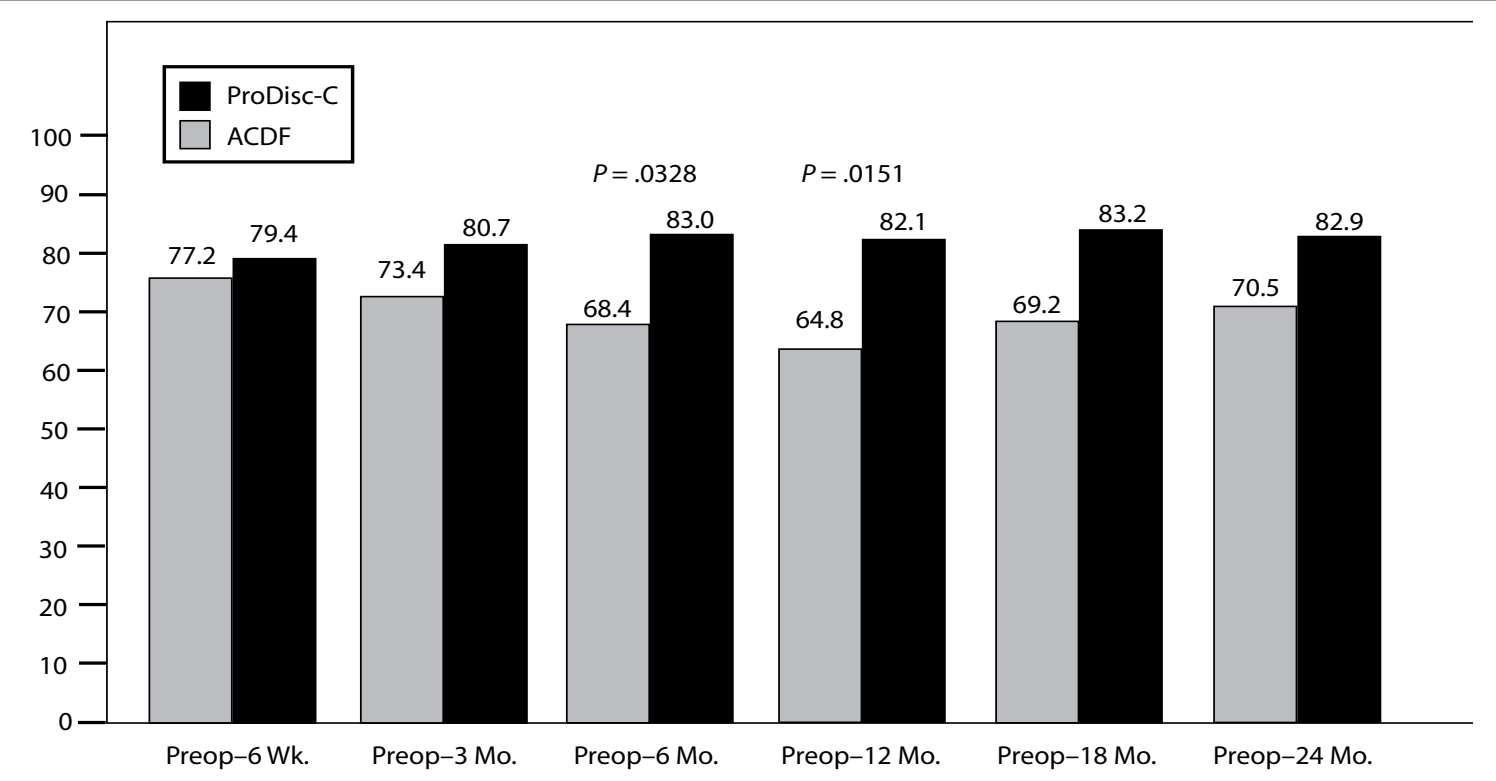

\section{DISCUSSION}

When considering the effectiveness of cervical total disc replacement (CTDR), it is important to distinguish it from lumbar total disc replacement (LTDR). LTDR is most commonly performed in the treatment of degenerative disk disease with axial back pain, while CTDR has been evaluated as a treatment for neurocompressive radiculopathy. Although both procedures are an alternative to fusion regarding the theoretical benefits that accompany motion preservation, the 2 procedures treat very different conditions and should not be equated. The outcomes of fusion for axial back pain are less predictable than those performed for cervical radiculopathy, and thus the level of success that LTDR must achieve in order to prove equivalence is not as high. Historically, excellent outcomes have been reported with cervical fusion; therefore, the challenge for any alternative procedure to show superiority is great.

Given this challenge it is not surprising that the first LTDR was performed over a decade before the first ProDisc-C was implanted in Europe in 2002. But CTDR has some distinct advantages over LTDR. These include a simpler and more widely utilized surgical approach, a less complicated revision approach, smaller loads, and potentially lower wear rates. If CTDR as an alternative to fusion could show equal or superior results, its rapid incorporation into most spine surgeons' armamentarium could be anticipated. 
This study suggests that at 2 years, the results of CTDR with this implant are at least equivalent to fusion in the treatment of symptomatic cervical disc disease. Given that longer-term data will be needed to assure that wear, loosening, or adjacent segment disease are not serious issues with CTDR, the results of this study should be interpreted with caution.

Figure 13. Mean Flexion-to-Extension Range of Motion in ProDisc-C Group.

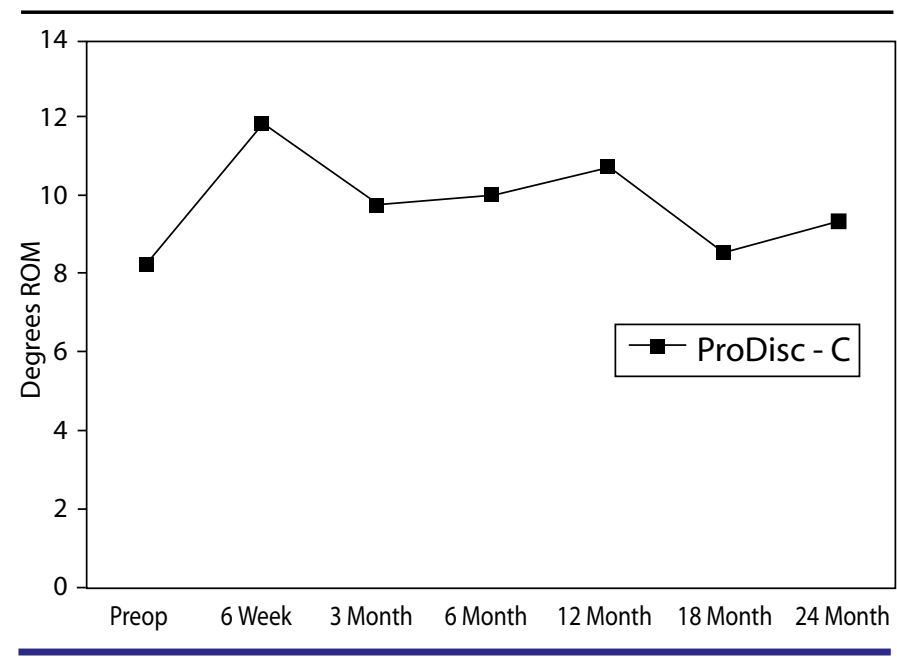

\section{Intraoperative Data}

Operative time for the disc replacement group was longer compared to the ACDF group (89.8 minutes versus 81.3 minutes, $P=.0112$ ). This difference in operative time is of doubtful clinical significance. Furthermore, the study did not allow for any non-randomized training cases to be performed; therefore the series includes many cases performed during the surgeons' learning curve. As greater experience is gained with the procedure, the operative time for cervical disc replacement would be expected to diminish. Estimated blood loss (EBL) was higher for the disc replacement group (96.6 cc versus $66.5 \mathrm{cc}, P=.004)$. The difference in EBL may be due to the keel cut into the endplates which creates bleeding from the cancellous bone. This difference in blood loss is also of doubtful clinical significance.

\section{Functional Outcome}

Although both the ACDF group and the disc replacement group showed improvements over preoperative data in all functional and pain parameters measured, the disc replacement group had statistically greater improvement. Because these findings were consistent across multiple outcome instruments (NDI, VAS, and SF-36), the likelihood that this is a random event is remote. Both the disc replacement group and the ACDF group achieved and maintained improvements in NDI, VAS arm and neck pain, and SF-36 PCS and MCS over baseline. The disc replacement group achieved and maintained greater improvements in the SF-36 PCS as compared to the ACDF group at 24-month follow-up. The improvements in neck and arm pain are similar to those described by Bertagnoli et al., ${ }^{17}$ a study that lacked a control group. Our results with respect to NDI, VAS, and SF36 are in concordance with more recent studies. ${ }^{18,19}$

The reasons for greater functional improvement in the disc replacement group are not completely clear. Regarding arm pain, it is possible that the disc replacement footprint is larger, on average, than the allografts used for fusion in the study, and therefore the prostheses are less likely to subside. Allograft fusions are known to undergo some subsidence, even in the presence of an anterior plate, and foraminal stenosis may result for some patients, causing recurrent or intermittent arm pain in the fusion group that would be less likely in the disc replacement group. Regarding neck pain, the increased pressures in the discs or facet joints adjacent to fusion may potentially result in neck pain. Also, it is conceivable that the reduced ability to adjust the segmental cervical alignment may create neck pain in some patients. Finally, it is possible that a more thorough decompression was associated with the patients who received arthroplasty because of the need to precisely place the implants. However, none of these relationships have been proven and remain speculative at this point.

\section{Patient Satisfaction}

Anterior cervical discectomy and fusion has evolved into the gold standard treatment for cervical radiculopathy and myelopathy. The clinical results of anterior cervical discectomy and fusion have been found to be quite reliable. It is interesting to note that the VAS satisfaction score for the disc replacement group was consistently higher at all time points throughout the study. A portion of this difference in patient satisfaction may be attributed to the fact that the patients knew they had received a new technology and there was some associated psychological benefit with this knowledge.

\section{Adverse Events}

Overall, the clinical complication rate for the ProDisc-C group was lower than for the fusion group. There were no cases of infection, implant loosening, or implant migration in the disc replacement group. Radiographically, 2 of the disc replacement patients developed spontaneous fusion across the anterior portion of the implant. However, in neither case did this result in a poor clinical outcome. Heterotopic ossification rates as high as $17.8 \%$ have been reported at one year for other cervical implants. ${ }^{20}$ In a European study utilizing the ProDisc$\mathrm{C}$, heterotopic ossification rate of $66 \%$ was documented. Surgical technique with respect to hemostasis, bone resection, and oral prophylaxis may have differed from our protocols; however these results may not be ignored. ${ }^{21}$

It is likely that some degree of heterotopic ossification represents a natural progression of spondylosis in some of these patients. In others, soft tissue handling, exposed cancellous surfaces, or perioperative hematoma may be the underlying cause. Meticulous hemostasis and the use of NSAIDs in 
the postoperative period, as sometimes indicated after joint replacement surgery, may ultimately play a role in reducing the incidence. The use of NSAIDs in the postoperative period was not a part of the study protocol. Waxing the keels and any bleeding cancellous surfaces may also be of benefit in heterotopic ossification prevention, but this remains to be seen. Ultimately, the heterotopic ossification that occurred had no clinical significance.

Radiographic complications in the fusion group included 6 cases of delayed union or pseudarthrosis. Pseudarthrosis was defined as greater than 3 degrees of motion or radiolucency at the host bone/allograft junction. One occurrence of pseudarthrosis led to significant subsidence and plate dislodgement, requiring repeat surgery.

\section{Limitations}

Although the minimum follow-up of 24 months represents one of the longest series to date in the literature, it is much too early to determine the ultimate efficacy of cervical disk replacement with ProDisc-C. Issues such as implant wear and adjacent segment disease will only be determined with further follow-up. Furthermore, although the study was blinded prior to surgery, patients were made aware of their postoperative status. Given that many patients who are willing to participate in a clinical trial may be biased in favor of new technology, those who received the disc replacement may rate their postoperative function and pain differently than those who received fusion.

\section{CONCLUSION}

This study indicates that cervical disc replacement using the ProDisc-C, at minimum, achieves equivalence when compared to ACDF for the treatment of symptomatic cervical disc disease in patients with at least 2-year follow-up. Reduced neck and arm pain, improved function, and fewer complications were observed. Patients in the disc replacement group had a statistically significant improvement in SF-36 PCS at 24 months. As well, patients in the disc replacement group had a statistically significant reduction in the rate of post-operative dysphagia at an average follow-up of 18 months. Whether these results will be maintained in the long-term and whether the implant will result in diminished rates of adjacent segment disk disease remains undetermined.

This manuscript was submitted December 4, 2007, and accepted for publication April 24, 2008.

The authors thank Eric B. Laxer, MD, Alfred L. Rhyne, III, $\mathrm{MD}$, and R. Alden Milam, MD, for enrolling patients into this randomized controlled clinical trial.

The authors also thank Ruth Beckham, Mandi Merriott, Caroline Ponce, and Katherine Prassas for coordinating this clinical trial.

\section{REFERENCES}

1. Smith GW, Robinson RA. The treatment of certain cervical-spine disorders by anterior removal of the intervertebral disc and interbody fusion. J Bone Joint Surg. 1958; 40-A(3):607-624.

2. Cloward RB. Vertebral body fusion for ruptured cervical discs. Am $J$ Surg. 1959; 98:722-727.

3. Bailey RW and Badgley CE. Stabilization of the cervical spine by anterior fusion. J Bone Joint Surg. 1960; 42-A: 565-594.

4. Drompp BW, Siebert WE, Fulgenzi WR. Early stabilization of certain fractures and fracture dislocations of the cervical spine. Experiences with interbody fusion via the anterior approach. Clin Orthop Relat Res. 1964; $34: 42-52$.

5. Bohlman HH, Emery SE, Goodfellow DB, Jones PK. Robinson anterior cervical discectomy and arthrodesis for cervical radiculopathy. Longterm follow-up of one hundred and twenty-two patients. J Bone Joint Surg. 1993; 75-A:1298-1307.

6. Gore DR, Sepic SB. Anterior discectomy and fusion for painful cervical disease. A report of 50 patients with an average follow-up of 21 years. Spine. 1998; 23:2047-2051.

7. Hilibrand AS, Carlson GD, Palumbo MA, Jones, PK, Bohlman HH. Radiculopathy and myelopathy at segments adjacent to the site of a previous anterior cervical arthrodesis. J Bone Joint Surg Am. 1999; 81(4):519-528

8. Ishihara H, Kanamori M, Kawaguchi Y, et al. Adjacent segment disease after anterior cervical interbody fusion. Spine J. 2004; 4(6):624-628.

9. Goffin J, Geusens E, Vantomme N, et al. Long-term follow-up after interbody fusion of the cervical spine. J Spinal Disord Tech. 2004; 17(2):79-85.

10. Hilibrand AS, Robbins M. Adjacent segment degeneration and adjacent segment disease: the consequences of spinal fusion? Spine J. 2004; 4(6 Suppl):190S-194S.

11. Dmitriev AE, Cunningham BW, Hu N, Sell G, Vigna F, McAfee PC. Adjacent level intradiscal pressure and segmental kinematics following a cervical total disc arthroplasty: an in vitro human cadaveric model. Spine. 2005; 30(10):1165-1172.

12. Sekhon LH, Sears W, Duggal N. Cervical arthroplasty after previous surgery: results of treating 24 discs in 15 patients. J Neurosurg Spine. $2005 ; 3(5): 335-341$.

13. Johnson JP, Lauryssen C, Cambron HO, et al. Sagittal alignment and the Bryan cervical artificial disc. Neurosurg Focus. 2004; 17(6):E14.

14. Sekhon LH. Cervical arthroplasty in the management of spondylotic myelopathy: 18-month results. Neurosurg Focus. 2004; 17(3):E8.

15. Pimenta L, McAfee PC, Cappuccino A, Bellera FP, Link HD. Clinical experience with the new artificial cervical PCM (Cervitech) disc. Spine J. 2004; 4(6 Suppl):315S-321S.

16. Anderson PA, Sasso RC, Rouleau JP, Carlson CS, Goffin J. The Bryan Cervical Disc: wear properties and early clinical results. Spine J. 2004; 4(6 Suppl):303S-309S.

17. Bertagnoli R, Yue JJ, Pfeiffer F, et al. Early results after ProDisc-C cervical disc replacement. J Neurosurg Spine. 2005; 2(4):403-410.

18. Pimenta L, McAfee PC, Cappuccino A, Cunningham BW, Diaz R, Coutinho E. Superiority of multilevel cervical arthroplasty outcomes versus single-level outcomes: 229 consecutive PCM prostheses. Spine. 2007; 32(12):1337-1344.

19. Sasso RC, Smucker JD, Hacker RJ, Heller JG. Clinical outcomes of Bryan cervical disc arthroplasty: a prospective, randomized, controlled, 


\section{SASJournal}

multicenter trial with 24-month follow-up. J Spinal Disord Tech. 2007; 20(7):481-491.

20. Leung C, Casey AT, Goffin J, et al. Clinical significance of heterotopic ossification in cervical disc replacement: a prospective multicenter clinical trial. Neurosurgery. 2005; 57(4):759-763.

21. Mehren C, Suchomel P, Grochulla F, et al. Heterotopic ossification in total cervical artificial disc replacement. Spine. 2006; 31(24):2802-2806. 